\title{
PYRIMIDINE METABOLISM IN MAN. V. THE MEASUREMENT IN VIVO OF THE BIOCHEMICAL EFFECT OF ANTINEOPLASTIC AGENTS IN ANIMAL AND HUMAN SUBJECTS *
}

\author{
By MITCHELL T. RABKIN, ELIZABETH W. FREDERICK, MYRON LOTZ $\dagger$ \\ AND LLOYD H. SMITH, JR. \\ (From the Departments of Medicine, Harvard Medical School and Massachusetts General \\ Hospital, Boston, Mass.)
}

(Submitted for publication September 25, 1961; accepted October 30, 1961)

\begin{abstract}
Many in vivo studies have been carried out on purine metabolism in man because of the presence of a readily available end product, uric acid. In the absence of a comparable unique end product, no previous over-all measurements of pyrimidine metabolism in the intact organism have been reported. Studies have been limited to the excretion of $\beta$-aminoisobutyric acid, as a metabolite of thymine (1), the incorporation of pyrimidine precursors into circulating leukocytes (2), the induced urinary excretion of orotic acid and orotidine ( 3 ), and the spontaneous urinary excretion of certain trace pyrimidines (4). In this report a method is described for evaluating pyrimidine nucleotide synthesis in the intact organism, based on the release of carbon dioxide- $\mathrm{C}^{14}$ from carboxyl-labeled pyrimidine precursors. The usefulness of this procedure in defining the onset, degree, and duration of action of certain antimetabolites is illustrated by studies in rats, and in patients with leukemia.
\end{abstract}

\section{MATERIALS AND METHODS}

Intravenous injections of labeled compounds were given through indwelling jugular vein catheters to male albino rats, weighing 125 to $150 \mathrm{~g}$. For collection of expired $\mathrm{C}^{14} \mathrm{O}_{2}$, air was flushed through a closed metabolic chamber and the carbon dioxide trapped in $3 \mathrm{~N} \mathrm{NaOH}$. Acidification of aliquots of this solution allowed trapping of the carbon dioxide in Hyamine base and counting in a Packard Tri-Carb liquid scintillation spectrometer at an efficiency of approximately 45 per cent. Indwelling cystostomy catheters were operatively placed in rats for urinary studies. Sedation with perphenazine (Trilafon, Schering), and hydration with normal or hypotonic saline

* This work was supported by Grant A-4080, National Institutes of Health, United States Public Health Service. Published in part in abstract form (J. clin. Invest. 1961, 40, 1073).

$\dagger$ Postdoctoral Research Fellow, National Institute of Arthritis and Metabolic Diseases. facilitated collections. Urine aliquots were counted with an efficiency of approximately 40 per cent. Orotic acid in the urine was identified by ascending paper chromatography in a propanol: $\mathrm{H}_{2} \mathrm{O}$ : formic acid system $(7: 2: 1)$ through comparison with known standard ( $\mathrm{Rf}$ approximately 0.40 ) and also from ultraviolet spectrophotometry of acid solutions of the eluted spots (5).

In human subjects, after intravenous injection of labeled compounds, expired air was collected in meteorological balloons. Measured aliquots were passed through $3 \mathrm{~N} \mathrm{NaOH}$, which was treated as in the rat assays.

Orotic acid- $\mathrm{C}^{14}\left(\mathrm{OA}-\mathrm{C}^{14}\right)$, labeled in either the $\mathrm{C}-6$ or C-7 (carboxyl) position, was purchased from the New England Nuclear Corporation. D,L-Carbamylaspartic acid- $\mathrm{C}^{14}\left(\mathrm{CAA}-\mathrm{C}^{14}\right)$, labeled in the ureide position, was synthesized as previously described (5). D,L-CAA-C $\mathrm{C}^{\mathbf{4}}$, labeled in the $\mathrm{C}-1$ position (corresponding to the carboxyl carbon of orotic acid), was synthesized by alkaline hydrolysis of carboxyl-labeled dihydroorotic acid-C $C^{16}$ (5). Specific activity as utilized was approximately $0.2 \mu \mathrm{c}$ per $\mu$ mole.

Other compounds used in these studies were gifts from the following sources: potassium oxonate, Dr. Robert E. Handschumacher; 6-azauridine, Dr. Emil Frei, III; 5fluoroorotic acid and azaserine, Dr. Thomas C. Hall; imidazoleacetic acid hydrochloride, Dr. Howard $\mathrm{H}$. Hiatt; 6-azauracil, Wellcome Research Laboratories; 2-ethylamino-1,3,4-thiadiazole, Lederle Laboratories Division of American Cyanamid Co.; Colcemide, Ciba Pharmaceutical Products, Inc. 6-Mercaptopurine was purchased from Nutritional Biochemicals Corp.

\section{RESULTS}

Validation of the method. In the biosynthetic sequence of pyrimidine nucleotide formation, an irreversible decarboxylation occurs in the conversion of orotidine- $5^{\prime}$-phosphate (O5P) to uridine-5'-phosphate (UMP) (Figure 1). In a partially purified system of orotidylic pyrophosphorylase and orotidylic decarboxylase from yeast, the release of $\mathrm{C}^{14} \mathrm{O}_{2}$ from carboxyl-labeled orotic acid has been shown to be a reliable measure in vitro of pyrimidine nucleotide formation (6). No evidence has yet been found for specific 


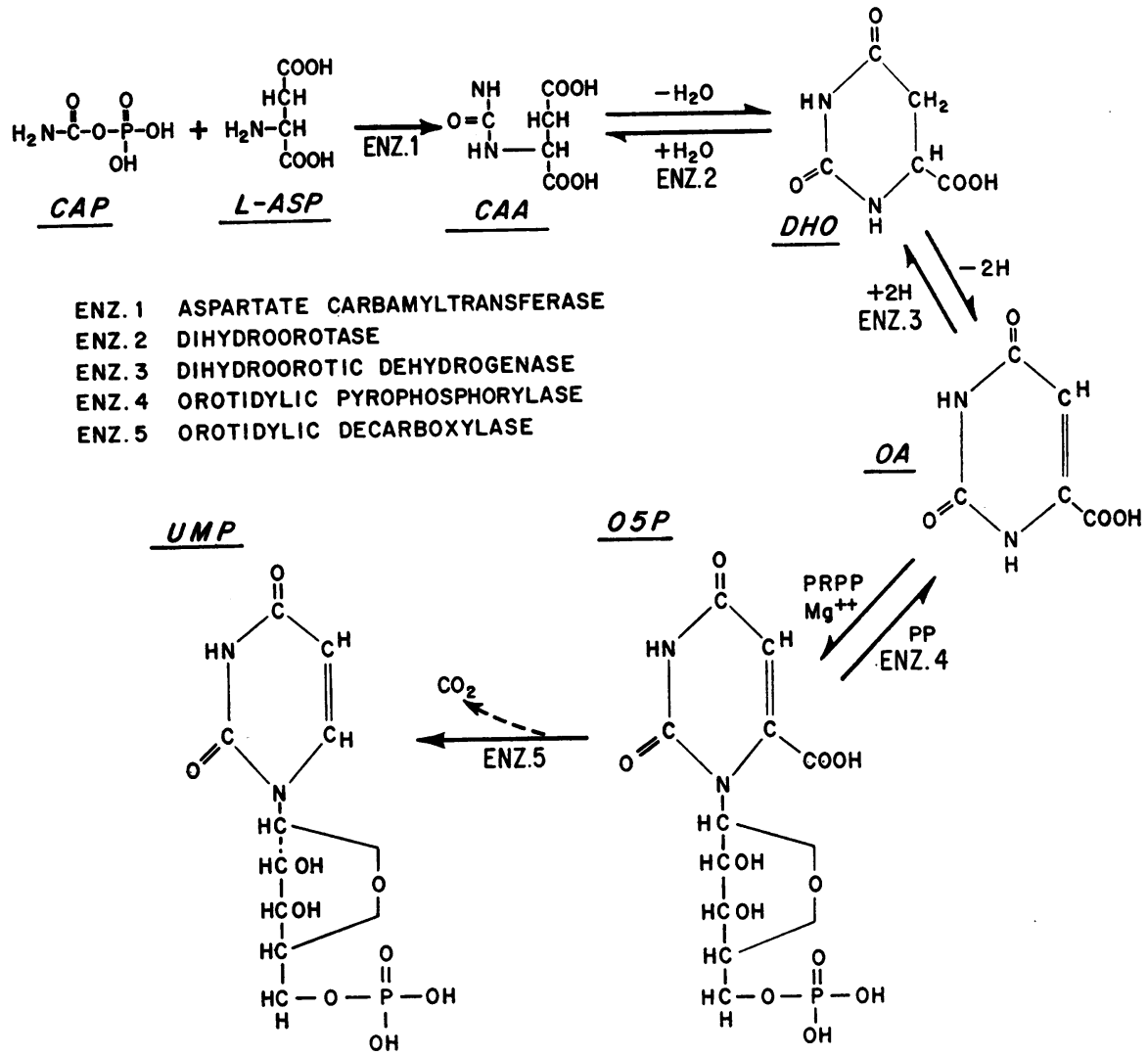

Fig. 1. Pathway of URIdine-5'-Phosphate biosynthesis. Abbreviations include: CAP, carbamyl phosphate ; L-ASP, L-aspartic acid ; CAA, carbamylaspartic acid; DHO, dihydroorotic acid; OA, orotic acid; PRPP, 5-phosphoribosylpyrophosphate; O5P,

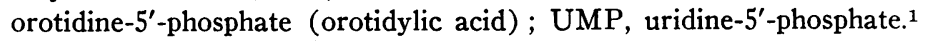

decarboxylation of orotidine- $5^{\prime}$-phosphate which does not lead to formation of uridine-5'-phosphate. Therefore, in the intact organism, the recovery of $\mathrm{C}^{14} \mathrm{O}_{2}$ in the expired air after injection of carboxyl-labeled precursors would be expected to reflect in vivo pyrimidine nucleotide synthesis. To support this hypothesis and to validate the specificity of the procedure as an

1 Classification numbers and systematic names of the enzymes are as follows: aspartate carbamyltransferase, 2.1.3.2, carbamoylphosphate: $\mathrm{L}$-aspartate carbamoyl transferase; dihydroorotase, 3.5.2.3, 4,5-L-dihydroorotate amidohydrolase; dihydroorotic dehydrogenase, 1.3.3.1, 4,5-L-dihydroorotate: $\mathrm{O}_{2}$ oxidoreductase; orotidylic pyrophosphorylase, 2.4.2.10, orotidine- 5 '-phosphate: pyrophosphate phosphoribosyltransferase; orotidylic decarboxylase, 4.1.1.23, orotidine-5'-phosphate carboxy-lyase. (Report of the Commission on Enzymes of the International Union of Biochemistry, New York, Pergamon Press, 1961.) index of pyrimidine biosynthesis, at least three postulates must be confirmed by experimental data: 1) $\mathrm{C}^{14} \mathrm{O}_{2}$ should be released more rapidly from precursors when the label is in the carbon atom destined to become the carboxyl group of O5P than when the isotopic carbon is elsewhere in the molecule; 2) antimetabolites whose action has been demonstrated in vitro to inhibit UMP synthesis should interfere with the respiratory excretion of $\mathrm{C}^{14} \mathrm{O}_{2}$ from carboxyl-labeled precursors given in vivo; 3) antimetabolites whose action is not directed toward pyrimidine biosynthesis should not "nonspecifically" interfere with the metabolism of the test compounds.

1) Degradative enzymatic systems have been described in mammalian preparations which release $\mathrm{CO}_{2}$ from pyrimidine precursors without prior formation of pyrimidine nucleotides $(7,8)$. The release of $\mathrm{C}^{14} \mathrm{O}_{2}$ by such catabolic pathways 
would be comparable from carboxyl- or noncarboxyl-labeled precursors. In contrast, a more rapid release of $\mathrm{C}^{14} \mathrm{O}_{2}$ from a carboxyl-labeled precursor should reflect a pathway of selective decarboxylation, such as that represented by orotidylic decarboxylase (enzyme 5, Figure 1). In Figure 2, a comparison is presented of the rates at which the rat expired $\mathrm{C}^{14} \mathrm{O}_{2}$ after the intravenous injection of $1.67 \mu$ moles per $100 \mathrm{~g}$ body weight of carboxyl-labeled or C-6-labeled orotic acid $\left(\mathrm{OA}-\mathrm{C}^{14}\right)$. Approximately 50 per cent of the isotope administered as carboxyl-labeled OA$\mathrm{C}^{14}$ appeared in the expired air in 1 hour; another 37 per cent was excreted in the urine. Intravenous injection of C-6-labeled OA-C $\mathrm{C}^{14}$ resulted in the respiratory recovery of less than 3 per cent of the administered radioactivity within 1 hour, but the excretion of similar amounts (32

TABLE I

Cumulative recovery of $C^{14}$ from orotic acid- $C^{\mathbf{1 4}}$ in rats

\begin{tabular}{|c|c|c|c|c|}
\hline Excretory product & & $20 \mathrm{~min}$ & $30 \mathrm{~min}$ & $60 \mathrm{~min}$ \\
\hline \multicolumn{5}{|c|}{ From carboxyl-labeled OA-C ${ }^{14}$} \\
\hline $\begin{array}{l}\text { Expired } \mathrm{C}^{14} \mathrm{O}_{2} \\
\text { Urinary } \mathrm{OA}-\mathrm{C}^{14}\end{array}$ & $\begin{array}{l}\text { Mean } \\
\mathrm{N} \\
\mathrm{SD}\end{array}$ & $\begin{array}{r}28.8 \% \\
17 \\
+6.4 \%\end{array}$ & $\begin{array}{r}35.0 \% \\
23 \\
+6.9 \% \\
34.6 \%\end{array}$ & $\begin{array}{c}49.9 \% \\
6 \\
37.2 \%\end{array}$ \\
\hline \multicolumn{5}{|c|}{ From ring $(\mathrm{C}-6)$ labeled OA-C ${ }^{14}$} \\
\hline $\begin{array}{l}\text { Expired } \mathrm{C}^{14} \mathrm{O}_{2} \\
\text { Urinary } \mathrm{O} A-\mathrm{C}^{14}\end{array}$ & & $0.5 \%$ & $\begin{array}{r}1.0 \% \\
30.7 \%\end{array}$ & $\begin{array}{r}2.8 \% \\
31.9 \%\end{array}$ \\
\hline
\end{tabular}

per cent) in the urine (Table I). Chromatographic studies revealed the urinary radioactivity to be that of unaltered orotic acid.

The first compound unique to pyrimidine biosynthesis is carbamylaspartic acid (CAA), which is converted by four enzymatic steps to UMP with loss of its 1-carboxyl group as $\mathrm{CO}_{2}$ (Figure 1). A similar comparison was made of the metabolism of carbamylaspartic acid-1- $\mathrm{C}^{14}$ with that labeled in the ureide carbon to test the validity of this decarboxylation as an index of UMP synthesis (Figure 3). After intravenous injection of D,L-carbamylaspartic acid-1-C ${ }^{14}$ (1.67 $\mu$ moles L-CAA per $100 \mathrm{~g}$ ), 32 per cent of the isotope administered as the L-form appeared as respiratory $\mathrm{CO}_{2}$ within 1 hour. After injection of similar amounts of ureide-labeled D,L-CAA-C ${ }^{14}$, only 6 per cent of the radioactivity was recovered in expired air within 1 hour. The urinary ex-

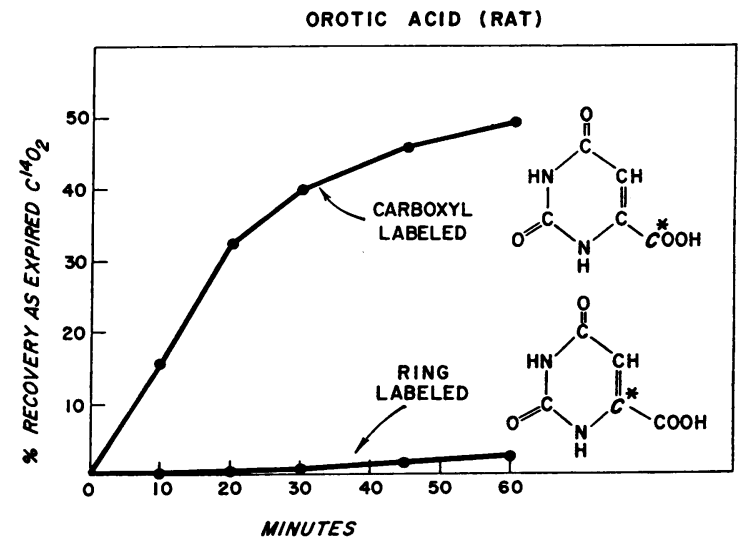

Fig. 2. Cumulative ReCovery OF eXPIREd $\mathrm{C}^{14} \mathrm{O}_{2}$ AFter INJECTION OF CARBOXYL- OR RING-LABELED OROTIC ACID-C ${ }^{14}$ IN THE RAT. $1.67 \mu$ moles per $100 \mathrm{~g}$ carboxyl-labeled OA$\mathrm{C}^{14}$ (upper curve, average of 6 experiments) and C-6labeled OA-C ${ }^{14}$ (lower curve, average of 3 experiments) injected intravenously.

cretion was approximately 47 per cent of the administered isotope. The fraction which represented the $\mathrm{D}$-isomer was not determined.

In summary, in vivo studies in the rat using selectively labeled pyrimidine precursors demonstrated a sharp contrast in the fate of the carboxyl- and noncarboxyl-carbons. This contrast supports the assumption that the measured release of $\mathrm{C}^{14} \mathrm{O}_{2}$ from the carboxyl carbon of these precursors is a reflection of the formation of UMP, the parent compound of pyrimidine nucleotides. In addition, it is apparent that in the dose

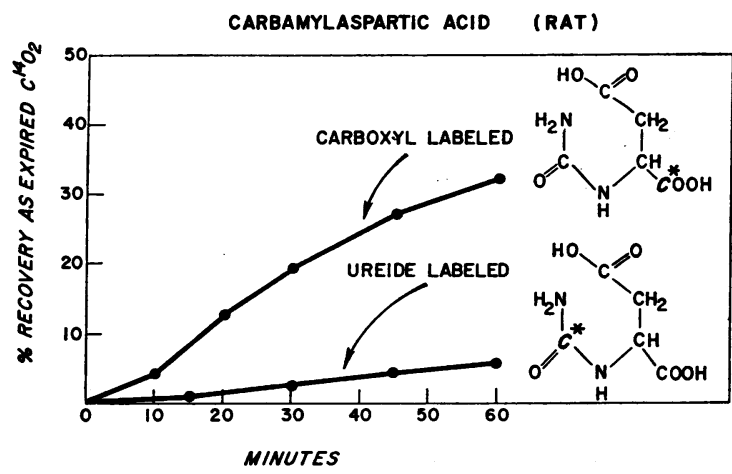

Fig. 3. Cumulative recovery OF expired $\mathrm{C}^{14} \mathrm{O}_{2}$ AFter INJECTION OF 1-CARBOXYL- OR UREIDE-LABELED D,L-CARBAMYLASPARTIC ACID-C ${ }^{16}$ IN THE RAT. $1.67 \mu$ moles per $100 \mathrm{~g}$ (as the L-isomer) 1-carboxyl-labeled D,L-CAA$C^{14}$ (upper curve, average of 3 experiments) and ureidelabeled D,L-CAA-C ${ }^{14}$ (lower curve, average of 2 experiments) injected intravenously. 
<smiles>O=C(O)c1cc(=O)[nH]c(=O)[nH]1</smiles>

OROTIC ACID<smiles>O=C(O)c1nc(O)nc(O)n1</smiles>

OXONIC ACID<smiles>O=C(O)c1[nH]c(=O)[nH]c(=O)c1F</smiles>

5-FLUOROOROTIC $A C I D$<smiles>O=c1cn[nH]c(=O)[nH]1</smiles>

6-AZAURACIL

Fig. 4. Structural formulas of the inhibitors of PYRIMIDINE NUCLEOTIDE BIOSYNTHESIS STUDIED.

range utilized, the catabolic degradation of the administered precursors was negligible.

2) The locus of action of a number of antineoplastic agents has been determined at an enzymatic level using well defined in vitro preparations. An antimetabolite, whose action has been elucidated by such studies to be inhibition of UMP synthesis, should interfere with the respiratory output of $\mathrm{C}^{14} \mathrm{O}_{2}$ from carboxyl-labeled precursors, as determined in the assay here employed. Three such antimetabolites were chosen to test this postulate-6-azauracil or its riboside, 6-azauridine, 5-fluoroorotic acid, and oxonic acid (Figure 4).

Extensive evidence has been presented that 6azauracil and 6-azauridine are converted enzymatically to 6-azauridylic acid (6AUMP) (9), which serves as a highly specific competitive inhibitor of orotidylic decarboxylase (10). The accumulation of orotidine in liver and tumors of rats (11) and the induction of orotic aciduria and orotidinuria in rats (12) and in man (3) after administration of 6-azauridine lend added support for the in vivo specificity of this inhibition, which blocks the conversion of orotidine-5'phosphate to uridine-5'-phosphate. Preliminary studies with 6-azauracil administered intraperitoneally to rats ( $440 \mu$ moles per $100 \mathrm{~g}$ body weight) showed marked inhibition of $\mathrm{C}^{14} \mathrm{O}_{2}$ recovery from carboxyl-labeled OA-C ${ }^{14}$ (Figure 5). The intraperitoneal injection of 6-azauridine ( 75

$\mu$ moles per $100 \mathrm{~g}$ body weight) led to an 80 per cent reduction in expired radioactivity, with a simultaneous 60 per cent increase in the radioactivity recovered in the urine over the 1 hour test period (Figure 6). Since diminished $\mathrm{C}^{14} \mathrm{O}_{2}$ evolution could be secondary to a loss of available substrate through increased renal excretion of orotic acid, a similar study with 6-azauridine pretreatment was carried out on an acutely nephrectomized rat. A corresponding reduction in the rate of $\mathrm{C}^{14} \mathrm{O}_{2}$ recovery demonstrated that the action of this antimetabolite was apparent regardless of renal function. With 1-carboxyllabeled $\mathrm{CAA}-\mathrm{C}^{14}$ as the pyrimidine precursor, preliminary treatment of the rat with 6-azauridine $(75 \mu$ moles per $100 \mathrm{~g})$ markedly inhibited pyrimidine nucleotide synthesis, as evidenced by an 80 per cent reduction in the rate of respiratory excretion of $\mathrm{C}^{14} \mathrm{O}_{2}$ (Figure 7 ). Since recovery of expired $\mathrm{C}^{14} \mathrm{O}_{2}$ is approximately linear with time over the first 30 minutes of each experiment (Figures 2,3), the data in Figures 5 and 7 have been expressed as an average rate rather than as

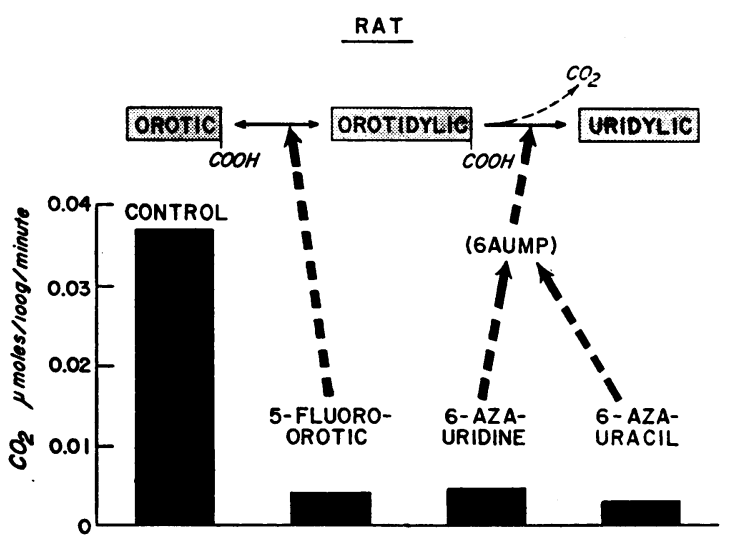

Fig. 5. EFFECT OF INHIBITORS OF PYRIMIDINE NUCLEOTIDE BIOSYNTHESIS ON METABOLISM OF ADMINISTERED OROTIC ACID in vivo. Each bar represents the average rate of conversion of intravenously administered carboxyl-labeled orotic acid- $\mathrm{C}^{14}$ to expired $\mathrm{C}^{14} \mathrm{O}_{2}$ over the first 30 minutes after its injection $(3.33 \mu$ moles per $100 \mathrm{~g})$ in the rat in representative individual experiments. Doses of antimetabolites: 5 -fluoroorotic acid, $27 \mu$ moles per 100 $\mathrm{g}$, intravenously, 5 minutes before orotic acid test dose; 6-azauridine, $75 \mu$ moles per $100 \mathrm{~g}$, intraperitoneally, 10 minutes before OA test dose; 6-azauracil, $440 \mu$ moles per $100 \mathrm{~g}$, intraperitoneally, 2 hours before OA test dose. Similar inhibition was obtained with orotic acid dosage of $1.67 \mu$ moles per $100 \mathrm{~g}$. (6-Azauridine- $5^{\prime}$-phosphate is abbreviated as 6AUMP.) 
cumulative total of respiratory output of radioactivity.

5-Fluoroorotic acid is an inhibitor at a number of steps in pyrimidine nucleotide and nucleic acid biosynthesis. These include inhibition of the 5methylation reaction in the formation of thymidylic acid (13), feedback inhibition of earlier stages of pyrimidine synthesis (14), and incorporation into "fraudulent" nucleic acids (15). In vitro studies have demonstrated that, as an orotic acid analogue, it also competitively inhibits the conversion of $\mathrm{OA}$ to $\mathrm{O} 5 \mathrm{P}$ by orotidylic pyrophosphorylase (enzyme 4, Figure 1) (16). The intravenous injection of 5-fluoroorotic acid (27 $\mu$ moles per $100 \mathrm{~g}) 10$ minutes prior to the injection of carboxyl-labeled orotic acid-C $\mathrm{C}^{14}$ (Figure 5 ) or 1-carboxyl-labeled carbamylaspartic acid$\mathrm{C}^{14}$ (Figure 7) resulted in marked inhibition of $\mathrm{C}^{14} \mathrm{O}_{2}$ excretion. The rates of recovery of $\mathrm{C}^{14} \mathrm{O}_{2}$ from $\mathrm{OA}-\mathrm{C}^{14}$ and $\mathrm{CAA}-\mathrm{C}^{14}$ were approximately 10 and 15 per cent of control, respectively.

Oxonic acid (2,4-dihydroxy-1,3,5-triazine-6-
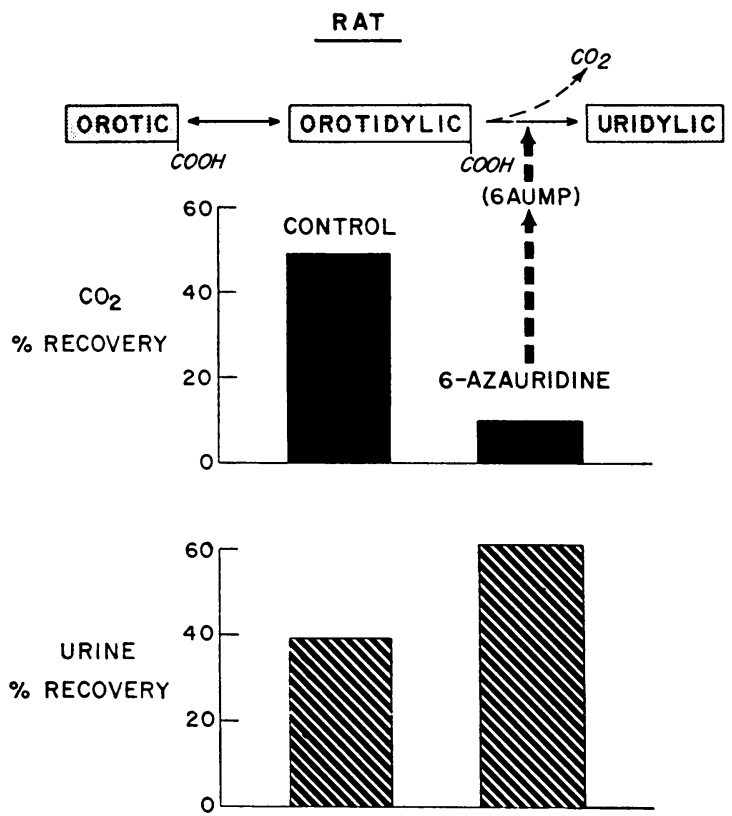

Fig. 6. EFFeCt of 6-AzAURIDINe on OROTIC ACID METABOLISM IN THE INTACT RAT. Left: recovery over 1 hour of intravenously administered carboxyl-labeled orotic acid- $\mathrm{C}^{14}(1.67 \mu$ moles per $100 \mathrm{~g})$ as expired $\mathrm{C}^{14} \mathrm{O}_{2}$ and as urinary $\mathrm{C}^{14}$. Right: the same indices after pretreatment with 6-azauridine $(75 \mu$ moles per $100 \mathrm{~g})$ injected intraperitoneally, 10 minutes before the test dose of orotic acid (average of 3 experiments).

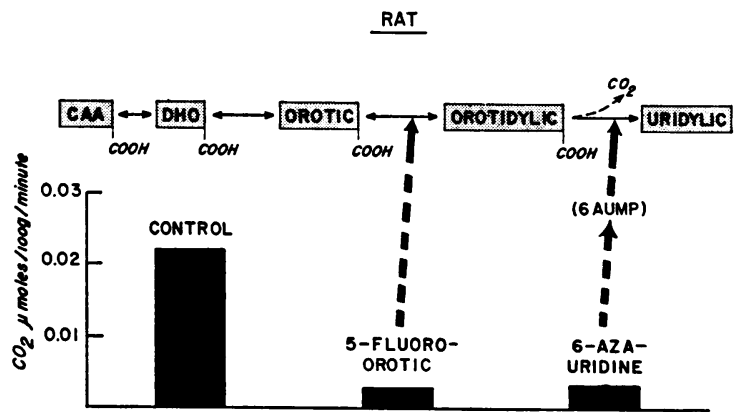

Fig. 7. EFFeCt of INhibitors of PyRIMIdine NUCleoTIDE BIOSYNTHESIS ON METABOLISM OF ADMINISTERED CARBAMYLASPARTIC ACID in vivo. Experimental conditions as in Figure 5. 1-Carboxyl-labeled D,L-CAA-C ${ }^{14}$ $(3.33 \mu$ moles as the L-form per $100 \mathrm{~g}$ ) was used as the pyrimidine precursor.

carboxylic acid) is an orotic acid analogue which exhibits an affinity approximately 1.5 times that of orotic acid for the enzyme, orotidylic pyrophosphorylase (17). It has been shown to have some antineoplastic effect in animals (18). In corroboration of studies with 6-azauridine and 5-fluoroorotic acid, the intravenous administration of oxonic acid $(1.67 \mu$ moles per $100 \mathrm{~g})$ as the potassium salt to a rat reduced recovery of $\mathrm{C}^{14} \mathrm{O}_{2}$ from carboxyl-labeled $\mathrm{OA}-\mathrm{C}^{14}$ to 6.8 per cent of the administered isotope at 30 minutes, in contrast to the control value of 35.0 per cent. This demonstration of inhibition is in agreement with the more detailed studies on oxonic acid by Handschumacher (17).

In summary, the three antimetabolites whose actions have been most clearly demonstrated in vitro to be that of interference with pyrimidine nucleotide biosynthesis markedly reduced the respiratory excretion of $\mathrm{C}^{14} \mathrm{O}_{2}$ from carboxyllabeled ${\mathrm{OA}-\mathrm{C}^{14}}^{14}$ or 1-carboxyl-labeled $\mathrm{CAA}-\mathrm{C}^{14}$ in the rat.

3) Although antimetabolites such as 6-azauridine, 5-fluoroorotic acid, and oxonic acid may have as a primary action inhibition of a single or several enzymatic steps in pyrimidine biosynthesis, widespread secondary effects may result due to the importance of pyrimidine nucleotides as cofactors in intermediary metabolism or as reactants in nucleic acid synthesis. If such a nonspecific disruption in cellular metabolism were the explanation for the antimetabolite-induced reduction in $\mathrm{C}^{14} \mathrm{O}_{2}$ excretion after carboxyl-labeled 


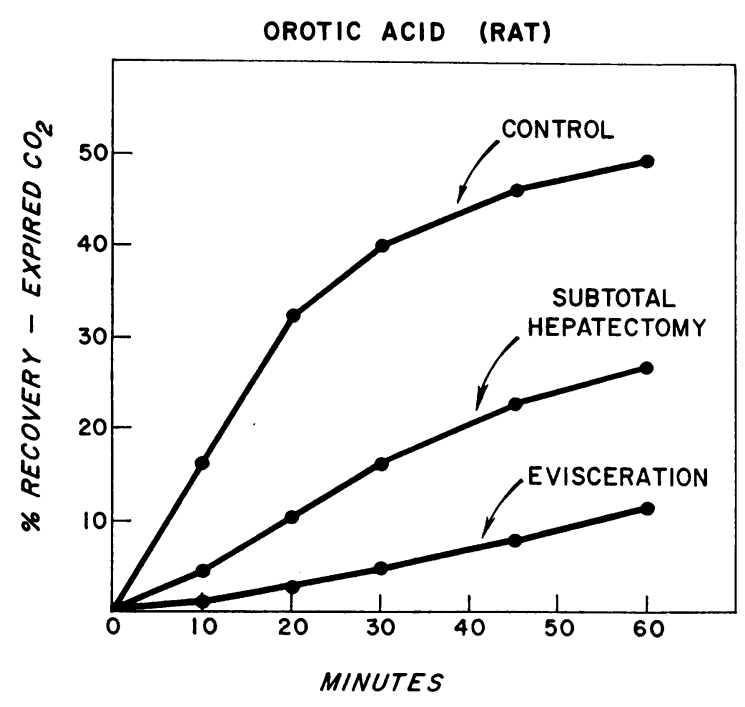

Fig. 8. EfFect of Subtotal hepatectomy and FuncTIONAL HEPATECTOMY WITH EVISCERATION ON METABOLISM OF ADMINISTERED CARBOXYL-LABELED OROTIC ACID-C ${ }^{14}$ TO EXPIRED $\mathrm{C}^{14} \mathrm{O}_{2}$ IN THE RAT.

$\mathrm{OA}-\mathrm{C}^{14}$ or 1-carboxyl-labeled CAA- $\mathrm{C}^{14}$ administration to the rat, similar effects should be found with analogous antimetabolites whose primary action is on purine synthetic pathways. As in the case of 5-fluoroorotic acid, 6-mercaptopurine exhibits a diversity of actions, which include feedback inhibition of earlier stages of purine biosynthesis (19), and interference with the conversion of inosine- $5^{\prime}$-phosphate to other purine nucleotides (20). The administration of an $\mathrm{LD}_{\overline{5} 0}$ dose (25 $\mathrm{mg}$ per $100 \mathrm{~g}$ ) of 6-mercaptopurine (21) to a rat caused less than a 10 per cent reduction in the respiratory $\mathrm{C}^{14} \mathrm{O}_{2}$ excretion from carboxyl-labeled OA-C ${ }^{14}$ injected 1 hour later.

Azaserine (O-diazoacetyl-L-serine) is a glutamine analogue, which has as its most important action an interference with the conversion of $\alpha$ $\mathrm{N}$-formylglycinamide ribotide to the corresponding amidine compound, in the pathway of $d e$ novo biosynthesis of purines (22). Azaserine, administered intraperitoneally to the rat in doses which cause a 75 per cent decrease in the incorporation of labeled glycine into the acid-soluble purine nucleotides of normal mouse liver (7.2 $\mathrm{mg}$ per $100 \mathrm{~g}$ ) (23), caused no reduction in the $\mathrm{C}^{14} \mathrm{O}_{2}$ excretion from carboxyl-labeled OA-C ${ }^{14}$ injected 10 minutes later.

2-Ethylamino-1,3,4-thiadiazole, a compound with antitumor effect in experimental animals
(24), exhibits a unique property of increasing uric acid synthesis in man unrelated to tissue destruction (25). Although the precise mechanism of its action has yet to be defined, indirect evidence suggests that it may participate as a nicotinamide analogue (26). Intraperitoneal injection of 2-ethylamino-1,3,4-thiadiazole in the maximum daily dose tolerated by the rat $(25 \mathrm{mg}$ per $100 \mathrm{~g}$ ) (24), did not affect the decarboxylation of carboxyl-labeled OA-C $\mathrm{C}^{14}$ administered $30 \mathrm{~min}$ utes later. Similarly, colchicine, administered intravenously as an $\mathrm{LD}_{20}$ dose of Colcemide (2 $\mathrm{mg}$ per $100 \mathrm{~g}$ ) (27), was without effect on the rate of $\mathrm{C}^{14} \mathrm{O}_{2}$ recovery in the test system.

In summary, antineoplastic agents whose sites of action are not in the pyrimidine biosynthetic sequence failed to inhibit significantly the release of $\mathrm{C}^{14} \mathrm{O}_{2}$ from carboxyl-labeled pyrimidine precursors.

Variables in the assay system. There are a number of variables inherent in this in vivo test system. Evidence concerning the site of metabolism of orotic acid in the rat was obtained by removal of two-thirds of the liver and by eviscerectomy with functional hepatectomy (28). These manipulations diminished $\mathrm{C}^{14} \mathrm{O}_{2}$ excretion by 60 and 85 per cent, respectively, suggesting that the liver is by far the major site of pyrimidine nucleotide synthesis from exogenous precursors (Figure 8). Since a third of the administered $\mathrm{OA}^{-\mathrm{C}^{14}}$ was lost in the urine within 30 minutes in the control rats, changes in renal function might be expected to affect the $\mathrm{C}^{14} \mathrm{O}_{2}$ recovery by altering substrate availability. Although total recovery of $\mathrm{C}^{14} \mathrm{O}_{2}$ was elevated 1 hour after injection of carboxyl-labeled OA-C $\mathrm{C}^{14}$ to an acutely nephrectomized rat, the initial rate over the first 30 minutes was not appreciably altered (Table II). In addition, while acute nephrectomy does not serve as a fully suitable control for the hepatec-

TABLE II

$$
\begin{gathered}
\text { Cumulative recovery of expired } C^{14} O_{2} \text { from } \\
\text { carboxyl-labeled } O A-C^{14}
\end{gathered}
$$

\begin{tabular}{lccc}
\hline \multicolumn{1}{c}{ Expt. group } & $20 \mathrm{~min}$ & $30 \mathrm{~min}$ & $60 \mathrm{~min}$ \\
\hline & $\%$ & $\%$ & $\%$ \\
Control & $28.8 \pm 6.4$ & $35.0 \pm 6.9$ & 49.1 \\
Nephrectomy & 24.6 & 42.4 & 68.1 \\
Nicotinamide & 23.3 & 30.6 & 39.1 \\
Imidazoleacetic acid & 23.0 & 30.8 & 43.1 \\
\hline
\end{tabular}


tomized animal, it does serve to show that anesthesia and surgical stress per se do not account for the loss of function in the hepatectomized animal.

The effect of increasing doses of administered carboxyl-labeled OA-C $\mathrm{C}^{\mathbf{1 4}}$ was studied to determine whether saturation of a limiting factor in orotic acid metabolism in the rat (transfer across cell membranes, enzyme concentration per se, availability of cofactors, and so forth) had been attained, or whether the administered isotope served merely to label the endogenous pool of the corresponding precursor. The recovery of $\mathrm{C}^{14} \mathrm{O}_{2}$ over the 30 minute test period was proportionate to the injected dose of carboxyl-labeled OA-C ${ }^{14}$ within the dose range studied (Figure 9). It was concluded that the dose of orotic acid most frequently used in the rat $(1.67 \mu$ moles per $100 \mathrm{~g})$ was not saturating.

The conversion of OA to O5P (enzyme 4, Figure 1) requires equimolar amounts of 5 -phos-

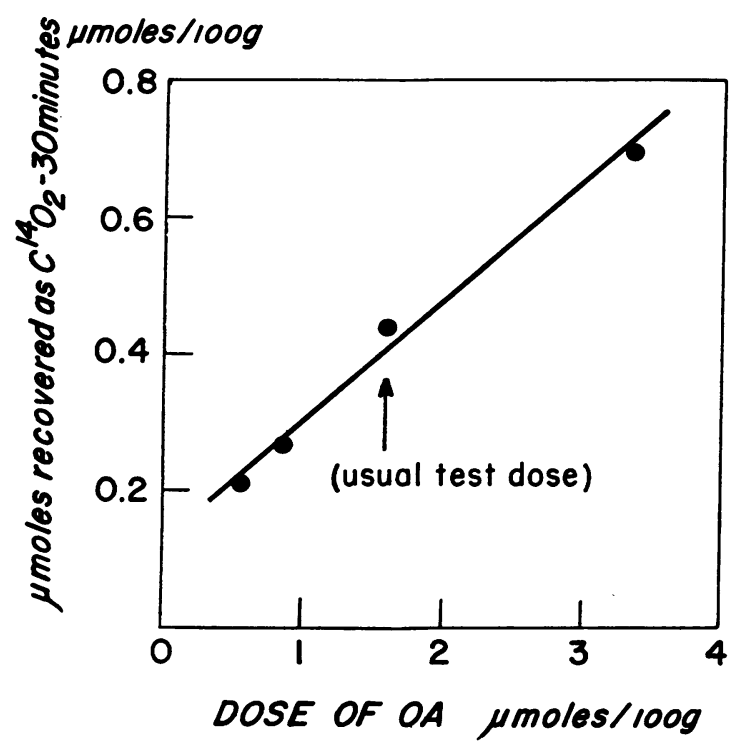

Fig. 9. BIOSYNTHETIC RESPONSE TO INCREASING DOSES OF OROTIC ACID. A comparison of the rates of recovery of expired $\mathrm{C}^{14} \mathrm{O}_{2}$ over 30 minutes after intravenous administration to the rat of varying doses of carboxyllabeled orotic acid- $\mathrm{C}^{\mathbf{1 4}}$. The ordinate is plotted as cpm recovered in expired $\mathrm{CO}_{2}$ /specific activity of OA-C ${ }^{14}$ injected; i.e., $\mu$ moles of orotic acid injected recoverable as $\mathrm{CO}_{2}$ over the experimental period. Three individual rats were given each dose of orotic acid at daily intervals. No effect on orotic acid metabolism could be attributed to the previous days' experiments.
TABLE III

Cumulative recovery of $C^{14}$ from carboxyl-labeled $O A-C^{14}$ in man

\begin{tabular}{ccccc}
\hline Subject & $30 \mathrm{~min}$ & $60 \mathrm{~min}$ & $120 \mathrm{~min}$ & $150 \mathrm{~min}$ \\
\hline & $\%$ & $\%$ & $\%$ & $\%$ \\
Normal volunteers & & & & \\
Expired $\mathrm{C}^{14} \mathrm{O}_{2}$ & & & & \\
1 & 11.1 & 21.8 & 38.1 & 44.0 \\
2 & 15.5 & 28.0 & 42.1 & 46.6 \\
3 & 20.2 & 32.4 & 48.5 & 53.8 \\
4 & 16.0 & 28.2 & 44.8 & 50.3 \\
Mean & 15.7 & 27.6 & 43.4 & 48.7 \\
Urinary $\mathrm{C}^{14}$ & & & & \\
1 & 25.4 & 29.0 & 30.3 & \\
2 & 38.3 & 43.7 & 44.3 & \\
3 & 29.2 & 31.1 & 32.0 & \\
4 & 30.8 & 33.6 & 34.6 & \\
Mean & 30.9 & 34.4 & 35.3 & \\
Leukemia patient M.B. & & & & \\
Expired C14 $\mathrm{O}_{2}$ & 17.4 & 30.1 & 44.0 & \\
Urinary C & & 20.1 & 20.5 & \\
\hline
\end{tabular}

phoribosylpyrophosphate (PRPP). An attempt was made to determine whether the availability of PRPP might become limiting in the formation of pyrimidine nucleotides, as reflected in this assay. In the rat, nicotinamide administration results in a marked increase in the hepatic content of DPN (29), formed by reactions utilizing PRPP and ATP (30). The administration of nicotinamide intraperitoneally in the rat in a dose which results in a tenfold increase in hepatic DPN $(50 \mathrm{mg}$ per $100 \mathrm{~g}$ ) (30), given 5 hours prior to challenge with carboxyl-labeled $\mathrm{OA}-\mathrm{C}^{14}$, did not significantly reduce $\mathrm{C}^{14} \mathrm{O}_{2}$ excretion (Table II).

Imidazoleacetic acid (IAA) is enzymatically coupled with PRPP to form the ribotide $(31,32)$, much of which subsequently appears as urinary imidazoleacetic acid riboside (33). A previous report of the urinary recovery of $25 \mu$ moles of IAA riboside per $100 \mathrm{~g}$ body weight in the rat (within 16 hours after intraperitoneal administration of $100 \mu$ moles IAA per $100 \mathrm{~g}$ ) suggested that the test dose of orotic acid administered in these experiments ( $1.67 \mu$ moles per $100 \mathrm{~g}$ ) should put no great demand on the availability of PRPP (34). In confirmation of this prediction, the injection of $300 \mu$ moles IAA per $100 \mathrm{~g}$ rat failed to reduce the metabolism of the carboxyl-labeled OA-C ${ }^{14}$ (Table II). 


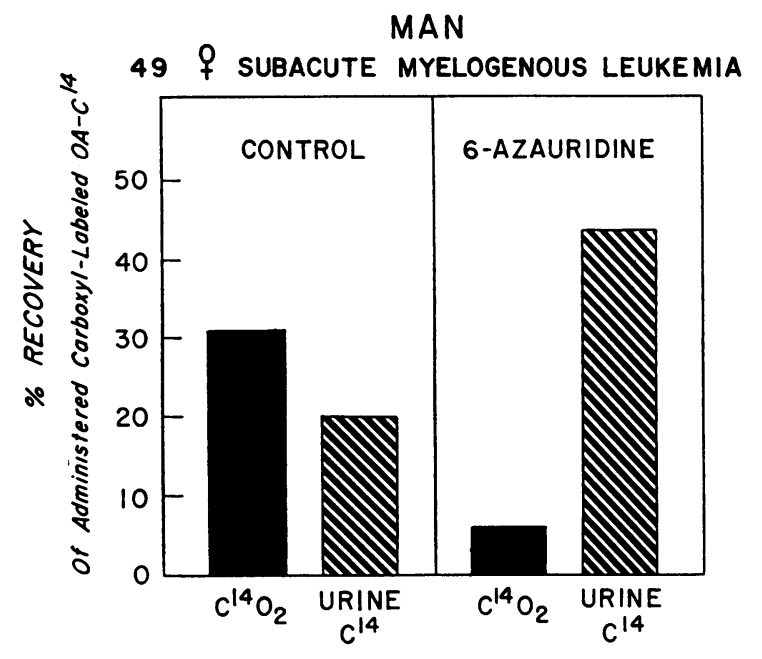

Fig. 10. EFFect of 6-Azauridine on orotic ACID METABOLISM IN MAN. Left: recovery over 1 hour of intravenously administered carboxyl-labeled orotic acid-C ${ }^{14}$ (1 $\mu$ mole per $\mathrm{kg}$ ) as respiratory $\mathrm{C}^{14} \mathrm{O}_{2}$ and as urinary $\mathrm{C}^{14}$. Right: the same indices after pretreatment with 6-azauridine ( $60 \mathrm{mg}$ per $\mathrm{kg}$ ) intravenously, 22 minutes before the test dose of orotic acid.

Studies in man. The metabolism of carboxyllabeled orotic acid-C $\mathrm{C}^{14}$ was studied in four normal volunteers. A trace dose of $1 \mu$ mole per $\mathrm{kg}$ (approximately $15 \mu \mathrm{c}$ total, with estimated $0.1 \mathrm{rad}$ exposure) was administered intravenously over 1 minute. Expired $\mathrm{CO}_{2}$ was quantitatively collected over the subsequent 2.5 hours (Table III). Cumulative recovery of the administered isotope as $\mathrm{C}^{14} \mathrm{O}_{2}$ averaged 27.6 per cent in 1 hour and 48.6 per cent at the end of 2.5 hours. An additional 35.3 per cent of the OA-C ${ }^{14}$ was accounted for in the urine, the major part being excreted in the first 30 minutes after injection.

Studies were carried out on a 49 year old woman (M.B.) with subacute myelogenous leukemia in partial remission. At the time of these studies her leukocyte count was 19,000 with a differential of polymorphonuclear leukocytes/57, bands/2, metamyelocytes/3, promyelocytes $/ 12$, blasts/2, lymphocytes/5, atypical lymphocytes/1, eosinophils/8, basophils/4, and monocytes/6. Control studies using $1 \mu$ mole carboxyl-labeled $\mathrm{OA}-\mathrm{C}^{14}$ per $\mathrm{kg}$ body weight revealed a rate of $\mathrm{C}^{14} \mathrm{O}_{2}$ excretion and urinary loss of OA-C ${ }^{14}$ comparable to that found in control subjects (Table III). After 6-azauridine pretreatment in the usual single therapeutic dose $(60 \mathrm{mg}$ per kg) (35), respiratory excretion of $\mathrm{C}^{14} \mathrm{O}_{2}$ was reduced by 80 per cent, and the urinary loss was increased by approximately 120 per cent during the 1 hour test period (Figure 10).

Onset and duration of antimetabolite effect. As an index of in vivo pyrimidine nucleotide biosynthesis, the recovery of respiratory $\mathrm{C}^{14} \mathrm{O}_{2}$ after administration of carboxyl-labeled pyrimidine precursors should allow information to be obtained concerning several aspects of the pharmacology of antineoplastic agents - the rapidity of action, the degree of inhibition, and the duration of the biochemical effectiveness. The degree of inhibition obtained has been illustrated above in the rat (Figures 5-7) and in man (Figure 10). The rapidity of onset of action of 6-azauridine in man was studied in two instances, one of which is illustrated in Figure 11. A constant infusion of carboxyllabeled $\mathrm{OA}-\mathrm{C}^{14}$ was administered throughout the experimental period to J.G., a 69 year old man with chronic lymphocytic leukemia. When equilibrium of $\mathrm{C}^{14} \mathrm{O}_{2}$ evolution was approached, 90 minutes after the start of the constant infusion, 6-azauridine ( $60 \mathrm{mg}$ per $\mathrm{kg}$ ) was rapidly injected intravenously. Diminution in respiratory $\mathrm{C}^{14} \mathrm{O}_{2}$ excretion was noted within the first 10-minute collection period. It has been demonstrated that the half-time of injected tracer bicarbonate in man is approximately 1 hour (36). This slow washout of the large total-body bicarbonate pool, interposed

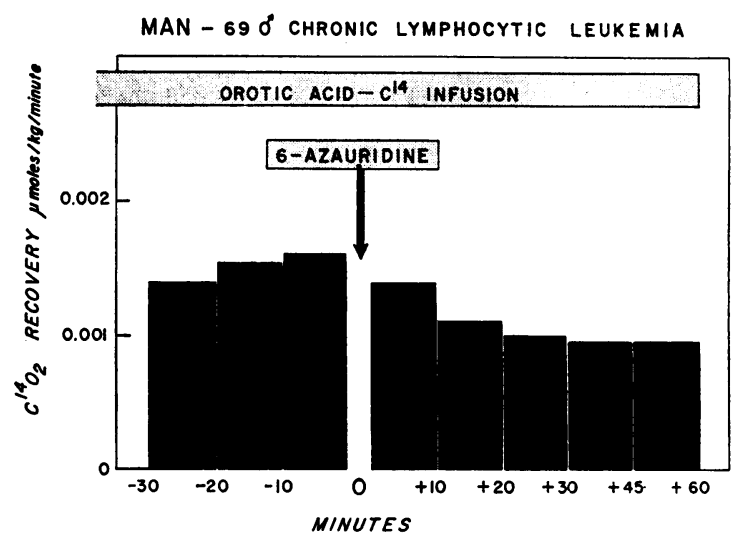

Fig. 11. Rapidity of action of 6-AZauridine in man. Successive time periods of collection of expired $\mathrm{C}^{14} \mathrm{O}_{2}$ with constant infusion of carboxyl-labeled orotic acid- $\mathrm{C}^{14}$, $0.005 \mu$ mole per minute per $\mathrm{kg}$. The infusion was started at time $=-90$ minutes. 6-Azauridine $(60 \mathrm{mg}$ per $\mathrm{kg})$ was given intravenously at zero time. 


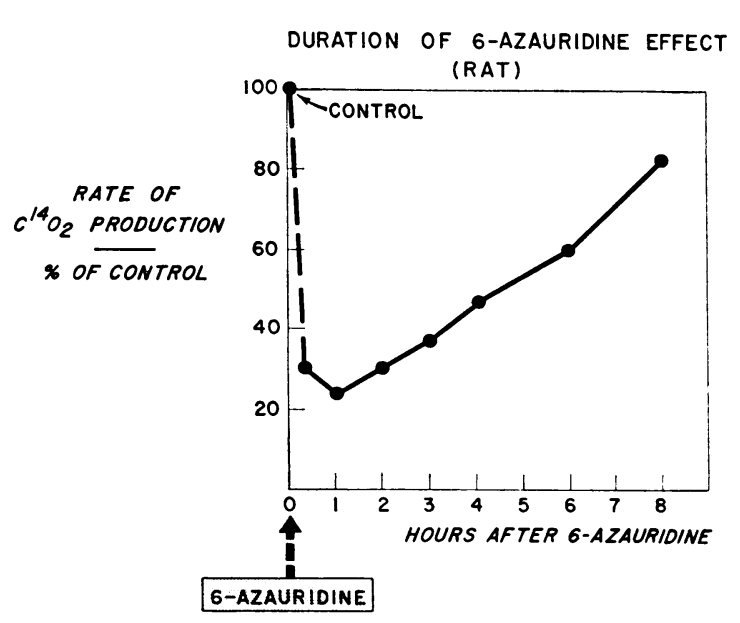

Fig. 12. Duration of 6-AZAuridine inhibition of PYRIMIDINE NUCLEOTIDE SYNTHESIS IN THE RAT. Each point represents data from an individual rat, showing the degree of antimetabolite-induced inhibition of respiratory $\mathrm{C}^{14} \mathrm{O}_{2}$ release from carboxyl-labeled orotic acid- $\mathrm{C}^{14}(1.67$ $\mu$ moles per $100 \mathrm{~g}$ ) injected intravenously at a specified time interval after the intraperitoneal injection of 6azauridine $(10 \mu$ moles per $100 \mathrm{~g})$. The ordinate is plotted as the output of $\mathrm{C}^{14} \mathrm{O}_{2}$ over 30 minutes after $\mathrm{OA}-\mathrm{C}^{14}$ injection with 6-azauridine pretreatment, compared to the same $\mathrm{C}^{14} \mathrm{O}_{2}$ collection (done a day earlier on the same rat) without use of the inhibitor. The abscissa represents the time interval between injection of 6 -azauridine and the subsequent injection of orotic acid- $\mathrm{C}^{\mathbf{1 4}}$.

between the release of $\mathrm{C}^{14} \mathrm{O}_{2}$ from carboxyl-labeled orotidine- $5^{\prime}$-phosphate and its recovery in the expired air, tends to obscure this measurement of rapidity of action. The extent of inhibition cannot be documented in this instance, because of a presumed increase in blood and tissue levels of orotic acid after administration of the antimetabolite.

More precise information was obtained in the series of experiments on rats summarized in Figure 12. Rats received test injections of carboxyllabeled orotic acid- $\mathrm{C}^{14}$ at varying intervals of time after an intravenously administered "therapeutic dose" of 6 -azauridine ( $10 \mu$ moles per 100 g) (9). Each point represents the rate of $\mathrm{C}^{14} \mathrm{O}_{2}$ evolution in an individual rat pretreated with 6-azauridine compared with its own previous control performance. The points for individual experiments are spread on an abscissa representing the time interval between 6-azauridine administration and the subsequent injection of the carboxyllabeled OA-C ${ }^{14}$. Marked depression of pyrimidine nucleotide synthesis was seen at the earliest interval studied, 20 minutes. The biochemical effectiveness of 6-azauridine as an inhibitory agent was progressively lost over the following 8 hours.

\section{DISCUSSION}

In the absence of a readily detectable end-product, pyrimidine metabolism in the intact organism has been studied by a variety of other approaches. Trace amounts of pyrimidine bases may be found in urine, most evident in patients with leukemia (4). This fraction is quantitatively much less important than that degraded through well defined pathways involving reduction to the corresponding dihydropyrimidine, hydrolysis of the ring, decarbamylation, and oxidative metabolism of the resulting $\beta$-amino acid $(7,8) . \quad \beta$-Aminoisobutyric acid, measured in urine, has been demonstrated to be derived at least in part from thymine degradation (7). The reliability of the presence of this metabolite as an index of pyrimidine degradation is reduced by the marked variability of its urinary excretion (1) and the demonstration that it may also be formed from valine (37).

Studies have been carried out on DNA synthesis in vivo, utilizing the incorporation of tritiated thymidine into hemic cells (2), and on the utilization of pyrimidine precursors by intact human leukocytes (38). Five sequential enzymes involved in the synthesis of UMP from carbamyl phosphate and aspartic acid have been assayed in human leukocytes and erythrocytes $(5,39)$. None of these methods allows a quantitative approach to the biosynthesis of pyrimidine nucleotides in the intact organism.

The conversion of O5P to UMP (enzyme 5, Figure 1) is effected by a specific irreversible decarboxylation in the only known pathway for the de novo synthesis of pyrimidine nucleotides (6). The rate of release of $\mathrm{CO}_{2}$ from O5P must therefore be a measure of the de novo synthesis of UMP. Two possible exceptions to this statement must be noted. First, O5P may be partially degraded by conversion to $\mathrm{OA}$, followed by catabolism via the dihydropyrimidine pathway as noted above. Such catabolic release of $\mathrm{CO}_{2}$ would not reflect pyrimidine nucleotide biosynthesis. Second, the existence of an alternate route for the de novo synthesis of pyrimidine nucleotides, not 
involving $\mathrm{O} 5 \mathrm{P}$, would invalidate the reliability of this decarboxylation as a metabolic index. Such an alternate pathway has not been demonstrated.

Experimental use of carboxyl-labeled O5P-C ${ }^{14}$ in vivo is not feasible, because of the limited penetration of phosphorylated compounds across the cell membrane. Carboxyl-labeled orotidine- $\mathrm{C}^{14}$ cannot be used as a precursor of carboxyl-labeled O5 $\mathrm{P}-\mathrm{C}^{14}$ because it is not enzymatically phosphorylated (9). In contrast, it is possible to use pyrimidine precursors with isotopic labeling of the carbon atom destined to become the carboxyl carbon of O5P. Not only are such precursors capable of crossing the cell membrane, but studies of their conversion to $\mathrm{UMP}$ and $\mathrm{C}^{14} \mathrm{O}_{2}$ via carboxyllabeled $\mathrm{O} 5 \mathrm{P}-\mathrm{C}^{14}$ may serve to integrate the activities of several enzymes in the pyrimidine biosynthetic pathway. In the present report, evidence has been presented to support the validity and specificity of this assay. In vivo administration of the labeled precursors has demonstrated that: 1 ) the release of $\mathrm{C}^{14} \mathrm{O}_{2}$ is much more rapid (6 to 10 times) after the injection of carboxyl-labeled $\mathrm{OA}^{-\mathrm{C}^{14}}$ or 1-carboxyl-labeled CAA-C $\mathrm{C}^{14}$ than after injection of precursors labeled elsewhere in the molecule; 2) three antineoplastic agents, which have been shown in vitro to inhibit pyrimidine nucleotide formation, markedly inhibited the release of $\mathrm{C}^{14} \mathrm{O}_{2}$ from carboxyl-labeled $\mathrm{OA}-\mathrm{C}^{14}$ and 1-carboxyl-labeled CAA-C ${ }^{14} ; 3$ ) antimetabolites active in the purine nucleotide synthetic sequence failed to exhibit such an inhibition. This evidence has been more fully discussed under Results.

Using C-6-labeled OA-C ${ }^{14}$, Hurlbert and Potter recovered 43 per cent of the isotope as pyrimidine nucleotides in rats sacrificed 2 hours after injection, with UMP achieving the highest initial specific activity (40). Similar doses of carboxyllabeled $\mathrm{OA}-\mathrm{C}^{14}$ administered to four rats in this laboratory resulted in the recovery of 49 per cent of the administered label in the expired air as $\mathrm{C}^{14} \mathrm{O}_{2}$ within 2 hours. Urinary losses were identical in both sets of experiments, and in each instance the liver was shown to be the major site of metabolism. The correspondence of these data further supports the reliability of measurement of expired $\mathrm{C}^{14} \mathrm{O}_{2}$ from carboxyl-labeled pyrimidine precursors as a direct reflection of pyrimidine nucleotide biosynthesis.
There are a number of limitations inherent in the assay system employed. The difficulties involved in deriving quantitative data from the use of such distal isotopic precursors in complex biological systems may include the effect of renal excretion on the blood level of administered precursor; the transport of the precursor across the cell membrane; its distribution within intracellular compartments; the enzyme content of cells ; availability of cofactors; the size, homogeneity and turnover rates of intra- and extracellular pools as well as other factors which control the appropriate activity of this biosynthetic chain of reactions.

The effect of certain of these variables on the assay system has been examined. Studies in nephrectomized rats have shown that reduction of renal excretion has no effect on the initial rate of $\mathrm{C}^{14} \mathrm{O}_{2}$ recovery (Table II). The linear response of $\mathrm{C}^{14} \mathrm{O}_{2}$ evolution to increasing doses of carboxyl-labeled OA-C ${ }^{14}$ (Figure 9) suggests that neither transport mechanisms into the cell, nor enzymatic capabilities within the cell were exceeded under the experimental conditions. Data have been presented which suggest that the availability of PRPP is not a limiting condition for OA metabolism in the test as employed. No information is available concerning the size of the body pool, or, more likely, heterogeneous body pools, of orotic acid or carbamylaspartic acid into which the isotopic test compound is distributed. The pool sizes and turnover rates of the compounds subsequently formed are also unknown. None of these compounds has been detected in plasma, so that it has been impossible to approximate pool sizes in vivo. A final important variant is the size and turnover rate of the total body bicarbonate pool, which intervenes between the enzymatic release of $\mathrm{C}^{14} \mathrm{O}_{2}$ and its subsequent appearance in the expired air.

In the absence of such information, the release of $\mathrm{C}^{14} \mathrm{O}_{2}$ from carboxyl-labeled $\mathrm{OA}-\mathrm{C}^{14}$ or 1-carboxyl-labeled CAA-C ${ }^{14}$ cannot be expressed in absolute terms of UMP synthesized. The isotopic precursor serves merely to label the $05 \mathrm{P}$ pool of unknown size, such that measurement of its metabolism to $\mathrm{C}^{14} \mathrm{O}_{2}$ is a reflection of UMP synthesis at that particular time in the intact organism. In addition to the de novo synthesis being studied here, it has also been demonstrated that 
pyrimidine nucleotides can be synthesized through reutilization of preformed pyrimidine bases (41). No information is available on the quantitative significance of this salvage synthesis under physiological conditions.

All of these variables may reduce the absolute quantitative significance of the assay system, but do not necessarily diminish its ability to document the direction, degree, and time sequence of certain changes in pyrimidine precursor metabolism within a given test subject. In practice, the respiratory excretion of $\mathrm{C}^{14} \mathrm{O}_{2}$ after administration of carboxyl-labeled $\mathrm{OA}-\mathrm{C}^{14}$ was reproducible in the individual rat and showed little variation among control rats (Table I) or among the few normal subjects studied (Table III). As an index, rather than as an absolute measurement of rate, the usefulness of this assay lies in reflecting changes in rates of de novo pyrimidine nucleotide synthesis within a given subject.

Most of the antineoplastic agents in current use have been developed as potential inhibitors of some phase of nucleic acid metabolism. Synthesized as analogues of known intermediates or cofactors in nucleic acid biosynthesis, their sites of action at an enzymatic level have often been determined with precision. The rational use of a chemotherapeutic agent is based not only on knowledge concerning its mechanism of action, but also on information concerning the rapidity of onset, degree, and duration of biochemical effectiveness. Data have been presented in this report to document the in vivo effect of 6-azauracil, 6-azauridine, 5 -fluoroorotic acid, and oxonic acid on UMP synthesis as reflected in $\mathrm{C}^{14} \mathrm{O}_{2}$ release from carboxyllabeled $\mathrm{OA}-\mathrm{C}^{14}$ or 1-carboxyl-labeled CAA-C ${ }^{14}$. Of greater importance, the assay system employed permits information to be obtained about the time sequence of change in pyrimidine metabolism after the administration of an antineoplastic agent (Figures 11, 12). Intraperitoneally administered 6-azauridine produced an inhibitory effect in the rat within 20 minutes (the shortest interval studied), which became maximal at 40 minutes. Thereafter, the inhibition of UMP synthesis by this antimetabolite was gradually lost over a period of 8 hours. It is of interest that previously published observations during experimental tumor chemotherapy in the mouse indicated that an 8-hour interval could not be exceeded for re- peated injections of 6-azauracil (which is also converted to 6-azauridylic acid in vivo) to maintain optimal therapeutic effect (42).

The diminution of $\mathrm{C}^{14} \mathrm{O}_{2}$ release from carboxyllabeled primidine precursors reflects the biochemical effectiveness of antimetabolites whose sites of action are on pyrimidine biosynthesis. No information is as yet available as to whether this index accurately reflects corresponding therapeutic effectiveness as antineoplastic agents.

\section{SUM MARY}

1. Evidence has been presented that the rate of respiratory $\mathrm{C}^{14} \mathrm{O}_{2}$ evolution from carboxyl-labeled pyrimidine precursors is an index of the synthesis in vivo of pyrimidine nucleotides.

2. The following observations support the specificity of this assay: A. The release of $\mathrm{C}^{14} \mathrm{O}_{2}$ was more rapid after the injection of carboxyl-labeled precursors than after injection of precursors labeled elsewhere in the molecule. B. Antineoplastic agents which have been shown in vitro to inhibit pyrimidine nucleotide formation markedly inhibited the release of $\mathrm{C}^{14} \mathrm{O}_{2}$ from carboxyl-labeled precursors. C. Antimetabolites active in the purine nucleotide synthetic sequence failed to exhibit such an inhibition.

3. The method has allowed information to be obtained concerning the rapidity in onset of action, the degree of inhibition attained, and the duration of biochemical effectiveness in vivo of certain antimetabolites which inhibit pyrimidine nucleotide biosynthesis.

\section{ACKNOWLEDGMENT}

The authors express their gratitude to $\mathrm{Dr}$. R. E. Handschumacher for his thoughtful review and helpful criticism of this work.

\section{REFERENCES}

1. Sutton, H. E. Beta-aminoisobutyricaciduria in The Metabolic Basis of Inherited Disease, J. B. Stanbury, J. B. Wyngaarden and D. S. Fredrickson, Eds. New York, Blakiston Division, McGrawHill, 1960, p. 792.

2. Rubini, J. R., Cronkite, E. P., Bond, V. P., and Fliedner, T. M. The metabolism and fate of tritiated thymidine in man. J. clin. Invest. 1960, 39, 909.

3. Habermann, V. Elimination by the urine of orotic acid and orotidine in man after application of 6-azauracil. Biochim. biophys. Acta 1960. 43, 137. 
4. Adams, W. S., Davis, F., and Nakatani, M. Purine and pyrimidine excretion in normal and leukemic subjects. Amer. J. Med. 1960, 28, 726.

5. Smith, L. H., Jr., and Baker, F. A. Pyrimidine metabolism in man. I. The biosynthesis of orotic acid. J. clin. Invest. 1959, 38, 798.

6. Lieberman, I., Kornberg, A., and Simms, E. S. Enzymatic synthesis of pyrimidine nucleotides. Orotidine $-5^{\prime}$-phosphate and uridine $-5^{\prime}$-phosphate. J. biol. Chem. 1955, 215, 403.

7. Fink, R. M., McGaughey, C., Cline, R. E., and Fink, $\mathrm{K}$. Metabolism of intermediate pyrimidine reduction products in vitro. J. biol. Chem. 1956, 218, 1.

8. Canellakis, E. S. Pyrimidine metabolism. I. Enzymatic pathways of uracil and thymine degradation. J. biol. Chem. 1956, 221, 315.

9. Pasternak, C. A., and Handschumacher, R. E. The biochemical activity of 6-azauridine: Interference with pyrimidine metabolism in transplantable mouse tumors. J. biol. Chem. 1959, 234, 2992.

10. Handschumacher, R. E. Orotidylic acid decarboxylase: Inhibition studies with azauridine 5'-phosphate. J. biol. Chem. 1960, 235, 2917.

11. Handschumacher, R. E., and Pasternak, C. A. Inhibition of orotidylic acid decarboxylase, a primary site of carcinostasis by 6-azauracil. Biochim. biophys. Acta 1958, 30, 451.

12. Habermann, V., and Sorrm, F. Mechanism of the cancerostatic action of 6-azauracil and its riboside. Coll. Czech. chem. Comm. 1958, 23, 2201.

13. Heidelberger, C., Chaudhuri, N. K., Danneberg, P., Mooren, D., Griesbach, L., Duschinsky, R., Schnitzer, R. J., Pleven, E., and Scheiner, J. Fluorinated pyrimidines, a new class of tumour-inhibitory compounds. Nature (Lond.) 1957, 179, 663.

14. Smith, L. H., Jr., and Sullivan, M. Feedback inhibition by fluorinated pyrimidines. Biochim. biophys. Acta 1960, 39, 554.

15. Chaudhuri, N. K., Montag, B. J., and Heidelberger, C. Studies on fluorinated pyrimidines. III. The metabolism of 5-fluorouracil-2-C $\mathrm{C}^{14}$ and 5-fluoroorotic-2-C ${ }^{14}$ acid in vivo. Cancer Res. 1958, 18, 318.

16. Stone, J. E., and Potter, V. R. Biochemical screening of pyrimidine antimetabolites. III. The testing of drugs against a system with a nonoxidative energy source. Cancer Res. 1957, 17, 800.

17. Handschumacher, R. E. Oxonate and other related inhibitors of the synthesis de novo of pyrimidine nucleotides. Cancer Res. Submitted for publication.

18. Bieber, S., Elion, G. B., Nathan, H. C., and Hitchings, G. H. The inhibition of mammary adenocarcinoma 755 by analogs of uracil (abstract). Proc. Amer. Ass. Cancer Res. 1957, 2, 188.

19. Gots, J. S., and Gollub, E. G. Purine analogs as feedback inhibitors. Proc. Soc. exp. Biol. (N. Y.) 1959, 101, 641.

20. Salser, J. S., Hutchison, D. J., and Balis, M. E. Studies on the mechanism of action of 6-mercapto- purine in cell-free preparations. J. biol. Chem. 1960, 235, 429.

21. Clarke, D. A., Philips, F. S., Sternberg, S. S., Stock, C. C., Elion, G. B., and Hitchings, G. H. 6-Mercaptopurine: Effects in mouse sarcoma 180 and in normal animals. Cancer Res. 1953, 13, 593.

22. Levenberg, B., and Buchanan, J. M. Formylglycinamidine ribotide and 5-aminoimidazole ribotide-Intermediates in the biosynthesis of inosinic acid de novo. J. Amer. chem. Soc. 1956, 78, 504.

23. Moore, E. C., and LePage, G. A. In vivo sensitivity of normal and neoplastic mouse tissues to azaserine. Cancer Res. 1957, 17, 804.

24. Oleson, J. J., Sloboda, A., Troy, W. P., Halliday, S. L., Landes, M. J., Angier, R. B., Semb, J., Cyr, $\mathrm{K}$, and Williams, J. H. The carcinostatic activity of some 2-amino-1,3,4-thiadiazoles. J. Amer. chem. Soc. 1955, 77, 6713 .

25. Krakoff, I. H., and Balis, M. E. Studies of the uricogenic effect of 2 -substituted thiadiazoles in man. J. clin. Invest. 1959, 38, 907.

26. Troy, W. P., Sloboda, A. S., Halliday, S. L., and Oleson, J. J. Derivatives of 2-amino-1,3,4-thiadiazole as niacin antagonists. Fed. Proc. 1956, 15, 372.

27. Schär, B., Loustalot, P., and Gross, F. Demecolcin (Substanz F), ein neues, aus Colchicum autumnale isoliertes Alkaloid mit starker antimitotischer wirkung. Klin. Wschr. 1954, 32, 49.

28. Russell, J. A. The anterior pituitary in the carbohydrate metabolism of the eviscerated rat. Amer. J. Physiol. 1942, 136, 95.

29. Kaplan, N. O., Goldin, A., Humphreys, S. R., Ciotti, M. M., and Stolzenbach, F. E. Pyridine nucleotide synthesis in the mouse. J. biol. Chem. 1956, 219, 287.

30. Imsande, J., and Handler, P. Biosynthesis of diphosphopyridine nucleotide. III. Nicotinic acid mononucleotide pyrophosphorylase. J. biol. Chem. 1961, 236, 525.

31. Fernandes, J. F., Castellani, O., and Plese, M. Biosynthesis of histamine ribotide and imidazoleacetate ribotide. Biochem. biophys. Res. Com. 1960, 3, 679 .

32. Crowley, G. M. Enzymatic synthesis of imidazoleacetic acid ribotide. Fed. Proc. 1960, 19, 309.

33. Tabor, H., and Hayaishi, O. The excretion of imidazoleacetic acid riboside following the administration of imidazoleacetic acid or histamine to rats. J. Amer. chem. Soc. 1955, 77, 505.

34. Hiatt, H. H. Studies of ribose metabolism. V. Factors influencing in vivo ribose synthesis in the rat. J. clin. Invest. 1958, 37, 1453.

35. Welch, A. D., Handschumacher, R. E., Finch, S. C., Jaffe, J. J., Cardoso, S. S., and Calabresi, P. A synopsis of recent investigations of 6-azauridine (NSC-32074). Cancer chemother. Rep. 1960, 9, 39.

36. Segal, S., Berman, M., and Blair, A. The metabolism of variously $C^{14}$-labeled glucose in man and 
an estimation of the extent of glucose metabolism by the hexose monophosphate pathway. J. clin. Invest. 1961, 40, 1263.

37. Kupiecki, F. P., and Coon, M. J. The enzymatic synthesis of $\beta$-aminoisobutyrate, a product of valine metabolism, and of $\beta$-alanine, a product of $\beta$-hydroxypropionate metabolism. J. biol. Chem. 1957, 229, 743.

38. Winzler, R. J. Differences in nucleic acid metabolism between normal and leukemic human leukocytes. Ann. N. Y. Acad. Sci. 1958, 75, 37.

39. Smith, L. H., Jr., Sullivan, M., and Huguley, C. M., Jr. Pyrimidine metabolism in man. IV. The en- zymatic defect of orotic aciduria. J. clin. Invest. 1961, 40, 656.

40. Hurlbert, R. B., and Potter, V. R. A survey of the metabolism of orotic acid in the rat. J. biol. Chem. 1952, 195, 257.

41. Canellakis, E. S. Pyrimidine metabolism. II. Enzymatic pathways of uracil anabolism. J. biol. Chem. 1957, 227, 329.

42. Hakala, M. T., Law, L. W., and Welch, A. D. Inhibitory activity of 6-azauracil, 6-uracil methyl sulfone, and related compounds on the growth of mouse lymphomas and sarcoma 180 (abstract). Proc. Amer. Ass. Cancer Res. 1956, 2, 113. 